Tropical Agricultural Pesearch \& Extension 20 (3 \& 4): 2017

\title{
GROUP DYNAMICS EFFECTIVENESS INDEX: A MEASURE OF GENDER CENTRIC APPROACH IN MUSSEL FARMING IN COASTAL KARNATAKA, INDIA
}

\author{
LPS Swathi*, G Sasikumar, AP Dineshbabu and P Rohit
}

Central Marine Fisheries Research Institute, Kochi - 680018, Kerala, India

\begin{abstract}
Today's extension trends represent a paradigm shift from top down approach to bottom up approach wherein the farmer is the central figure in the technology adoption and technology refinement process. Research and extension organizations have moved from working with individual farmers to collaboration with groups. Members of a group collectively take part in accessing and sharing resources, in decision making, partaking of benefits, than while acting individually. The Participatory Action model (PAM) was used for the transfer of technology to Mussel farmers, through a six step process of planning and implementation. Mussel farming connotes the scientific culture of edible bivalves which belong to the family "Mytilidae". The economic by product of mussel farming is the mussel meat which has considerable commercial value and fetches additional source of income for fishermen during the lean fishing seasons. Mussel faming in India is carried out as individual ownership, family ownership and ownership by self-help groups. In the present study, the Participatory Action Model was used as a method to organize the self-help groups involved in mussel farming. This model aims at development of group capacities through involvement of the group members in planning, implementation, review and reflection process in mussel farming undertaken on a group basis. The study aimed at assessing the Group Dynamics Effectiveness of men and women mussel farmers in their respective groups. The findings revealed that the overall Group Effectiveness Index (G.E.I) was 63.03, which has been achieved, within a short period of three years of technology transfer. Results of Chi-square analysis revealed that there was significant association between men and women farmers in the groups with respect to group dimensions such as influence, styles of influence, decision making, task function, feelings, norms, interpersonal trust and group achievements at $(P<0.05)$. The findings of the discriminant analysis revealed that the group dimensions which significantly discriminated the men and women farmers, were achievements of group, norms, interpersonal trust and empathy. The study implies that there is tremendous potential for harnessing the group efforts for successful adoption of the technology and future participatory efforts should be directed at strengthening these specific dimensions which govern the group behaviour and which in turn accentuate the G.E.I.
\end{abstract}

Key Words: Mussel farmer, Participatory Action Model, Group Effectiveness Index

\section{INTRODUCTION}

Extension approaches over the past few decades has undergone a major metamorphosis involving new players in the process of technology development, technology transfer and refinement. A multi stakeholder approach to service delivery in general and innovation development in particular has become essential more so in the mussel farming scenario. Fisheries extension system has to help farm men and women to organize themselves in ways which empower them. An intrinsic characteristic of farmers is that they innovate to sustain, expand and improve their production systems. Hence, adoption of new technologies by farmers is a product of social negotiation among stakeholders. The spreading of this innovation is only possible through effective social organisation and communication at community level (Hagmann et al., 1999, Padre et al., 2003, Defoer et al., 2002). 
The Participative Action Management model (PAM) (Chamala, 1990) is a major paradigm shift in the way technology is developed and adopted by stakeholders. The top down centralized extension approach is slowly losing its significance as the farmer takes on the center stage in the technology transfer and adoption process. The PAM model is a management model where all relevant agencies, groups and individuals with a common interest in research and development come together to facilitate joint problem solving. The group works for the benefit of the partners. Mussel farming has been successfully adopted in the northern districts of Kerala by farmers groups and has come to be a mainstay of the coastal economy of these regions due to the profitability of the enterprise. (Kripa and Mohamed 2008, Laxmilatha, et al., 2009). In the Coastal State of Karnataka, India, the PAM model of technology transfer for green mussel culture, implemented at Saligramma village of Udupi district by the Scientists at Central Marine Fisheries Research Institute, Mangalore, has spearheaded the groups' activities and co-coordinated the effective functioning of the groups in using adult learning principles and action learning processes. The average production of each mussel farmer group was estimated at $3000 \mathrm{~kg} / \mathrm{crop}$, yielding a revenue of Rs. 50,000 in six months. The mussels were sold to export houses in Udupi, Karnataka at a premium price of Rs.55/ $\mathrm{kg}$. This successful transfer of technology using the PAM model, necessitated the study of the dynamics of group behaviour among the target groups and was undertaken with the following objectives.

To assess the group dynamics effectiveness index of the mussel farmers, to study the association between men and women farmers with respect to the dimensions of Group Dynamics and also to study the factors which discriminate between men and women farmers with respect to their group dynamics effectiveness index.

\section{MATERIALS AND METHODS}

The study was conducted in Saligramma village, Kundapur taluk, Udupi district of Karnataka. The village was purposively selected since it harbored the maximum number of mussel farmers in the State of Karnataka. The Participative Action Model (PAM) model developed by Chamala (1990) was used for the six step participatory planning, technology transfer and adoption process as depicted below (Figure $1)$.

Participatory Rural Appraisal techniques such as conduct of focus group discussions, drawing of resource maps, social maps, farm maps, undertaking of transects, seasonal diagrams were done, involving the mussel farmers in the villages (Plate 1). The resource map helps the farmers to know the various resources available in the village such as water bodies, estuaries, availability of fish species community wells, soil pattern and drainage points. On the other hand drawing of social maps throws more light on farmers' organizations, women groups, leadership styles and patterns in the groups and

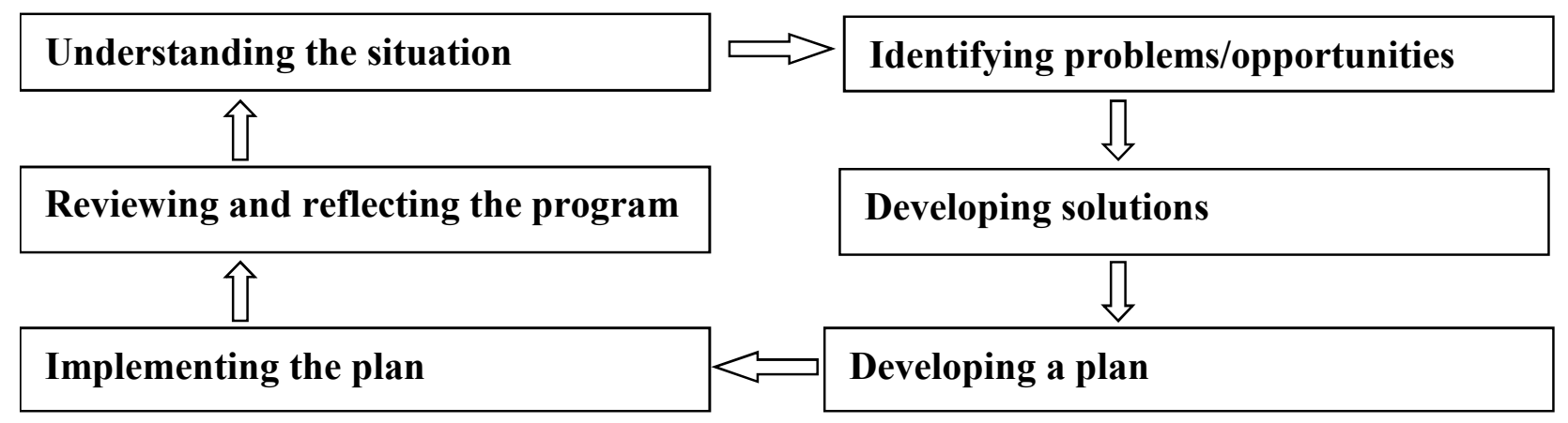

Figure 1: Participatory Action Model (PAM) 
community, family types and sources of credit available as well as made use of by the farmer. Seasonal diagrams are intended to know the seasons of mussel culture, collection of mussel seeds, seeding the ropes, suspending the seeded ropes in rafts and time of harvest of the crop. The PAM approach calls for major shifts in attitudes and ways of working, from closed to open, from individuals to groups, from collecting to sharing information, from verbal to visual communication and from "researcher-to-village" and to "Village-to-Village information flow.

Following the six step process in the PAM, the farmers were encouraged to develop a plan of action for the successful method demonstration of mussel culture in their farms. There were five farmers groups, constituting a total sample size of 30 (18 men and 12 women). All the 30 farmers involved in mussel farming were considered for the present study. The sampling method used for the present study was purposive sampling since all the mussel farmers involved in mussel culture activity (including both men and women) were selected for the study. At present, the five groups of farmers have successfully adopted mussel culture in their farms. In order to study the effectiveness of the group dynamics among these farmers an ex-post facto research design was used. An ex-post facto research design is a method in which groups with qualities that already exist are compared on some dependent variable. Also known as "after the fact" research, an ex post facto design is considered quasi-experimental because the subjects are not randomly assigned - they are grouped based on a particular characteristic or trait. The Group Dynamics Effectiveness Index (G.D.E.I.) developed by Vipinkumar (1998) was used for the study. A well structured interview schedule was used to collect the data from the respondents. Thirteen dimensions of G.D.E.I used were Participation, Influence, styles of influence, decision making procedures, task functions, maintenance functions, group atmosphere, membership, feelings, norms, empathy, interpersonal trust and achievements of the group. Judges rating was used to assign weightages for each sub dimension studied. The G.D.E.I was computed by adding the scores of each sub dimension, multiplying them with their respective weightages by using scale product method, and adding up the scores of all sub dimensions to get the G.D.E.I for each respondent. The data collected was tabulated and analyzed using appropriate statistical techniques such as mean, standard deviation, chisquare analysis and step wise discriminant function analysis. The statistical software SPSS version 16.0 was used for the analysis of the collected data.

\section{RESULTS AND DISCUSSION}

Figure 2 shows that the G.D.E.I. of male farmers in the group ranged from 45.1 to 95.2 and for female farmers, it ranged from 49.10 to 60.30. The average G.D.E.I. for males was 68.03 and for females 55.04. The overall G.D.E.I. was 63.03. In close agreement with this finding, Vipinkumar (1998) stated that the overall G.D.E.I. of Self Help Groups among Horticulture farmers was 55.

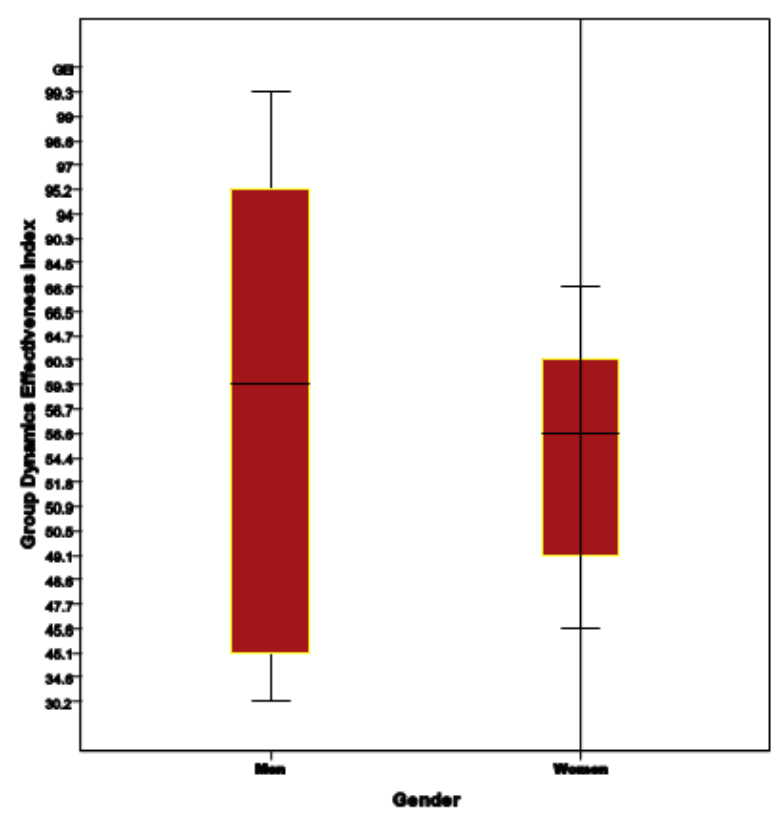

Figure 2. Group Effectiveness Index for Mussel Farmers based on Gender Wise 
A perusal of Table 1 revealed that, of the 13 group dimensions studied, there existed significant association between male and female farmers with respect to dimensions such as influence, styles of influence, decisionmaking, task function, feelings, norms, interpersonal trust and group achievements. It was observed that male farmers exhibited greater roles in influencing group members, in leading the group, in undertaking decisions, task functions and they scored relatively higher than the female farmers in coordinating the feelings in the group, maintaining the norms, interpersonal trust and group achievements. These findings are in line with the findings of World Bank Study (2009) which reported that despite overwhelming participation of women in famers groups, men still retain significant control over decision making.

An observation of Table 2 revealed that, of the 13 group dimensions studied, only dimensions such as achievements of group, norms, interpersonal trust and empathy significantly discriminated male and female farmers. The increased differential scores in group achievements and norms would increase the difference between the group effectiveness of male and female farmers, whereas increased score on dimensions of interpersonal trust and empathy differentiated less between the group effectiveness of male and female farmers (Fig 4).

Table 1: Chi-square analysis between male and female farmers with respect to their group dimensions $(\mathbf{n}=\mathbf{3 0})$

\begin{tabular}{|c|c|c|c|}
\hline $\begin{array}{l}\text { Sl. } \\
\text { no }\end{array}$ & Group dimensions & $\overline{\text { Df }}$ & $\begin{array}{l}\text { Chi-square } \\
\text { value }\left(X^{2}\right)\end{array}$ \\
\hline 1 & Participation & 9 & 0.64 \\
\hline 2 & Influence & 7 & $16.06 *$ \\
\hline 3 & Styles of influence & 10 & $18.19 *$ \\
\hline 4 & Decision making & 8 & $21.25 *$ \\
\hline 5 & Task function & 5 & $11.47^{*}$ \\
\hline 6 & $\begin{array}{l}\text { Maintenance func- } \\
\text { tion }\end{array}$ & 7 & 7.89 \\
\hline 7 & Group atmosphere & 5 & 8.10 \\
\hline 8 & Membership & 7 & 8.13 \\
\hline 9 & Feelings & 9 & $20.40 *$ \\
\hline 10 & Norms & 7 & $25.83 * *$ \\
\hline 11 & Empathy & 7 & 9.23 \\
\hline 12 & Interpersonal trust & 6 & $18.79 *$ \\
\hline 13 & Group Achievements & 12 & 25.13* \\
\hline
\end{tabular}
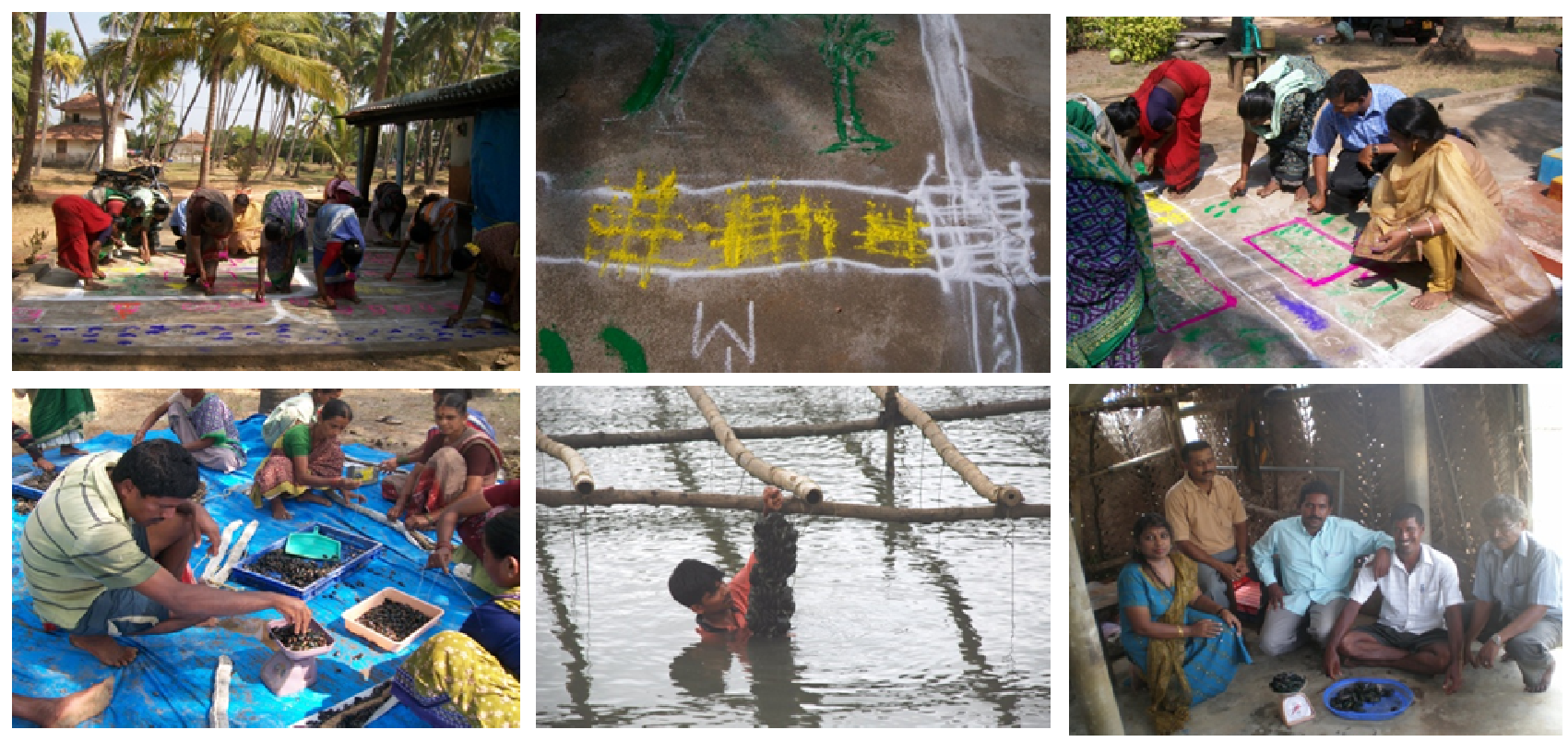

Plate 1: Mussel farmers involved in drawing social maps, resource maps and joint participation in mussel seeding activities 
For the following study, the achievements of the group were operationalized as the level of performance of the group as perceived by the farmer as well as the performance of the farmer himself as the group member. Norms on the other hand, were operationalized as the extent to which the farmer feels the standards or ground rules and regulations which are in operation that control the behavior of group members for the smooth functioning of the group. The factors which discriminated male and female farmers were achievements of the group and norms of the group. This mean that male and female farmers differed with respect to these two factors. As was observed in the study, female farmers activities were restricted to activities such as collection of mussel seeds from the wild for farming, seeding of the ropes and maintenance of the mussel farms. Male farmers on the other hand, took the lead in assessing credit requirement, approaching banks and financial institutions for loans as well as marketing of the produce. Dimensions of group dynamics such as inter personal trust and empathy. It could be inferred that, these groups engaged in mussel farming were socially well knit cohesive units where mutual trust and empathy towards group members were well defined and reciprocated.

Table 2: Discriminant Function for Male and Female Farmers

\begin{tabular}{llcc}
\hline $\begin{array}{l}\text { SI } \\
\text { no }\end{array}$ & $\begin{array}{l}\text { Group } \\
\text { dimensions }\end{array}$ & $\begin{array}{l}\text { Discriminant } \\
\text { Co-efficient }\end{array}$ & $\begin{array}{l}\text { Structure } \\
\text { matrix } \\
\text { Co- } \\
\text { efficient }\end{array}$ \\
\hline 1 & $\begin{array}{l}\text { Achievements } \\
\text { of group }\end{array}$ & 1.23 & 0.37 \\
2 & Norms & 0.92 & 0.35 \\
3 & Interpersonal & -1.32 & -0.13 \\
& trust & -0.65 & -0.09 \\
\hline & Empathy & & \\
\hline
\end{tabular}

* Significant, $\mathrm{P}<0.05$,

Canonical correlation $=0.85$

Wilk's Lambda $=0.742 * *$

Overall percentage of correct classification $=$ $93.3 \%$
Conversely, related studies from the North Western part of Kerala State, in Kasaragod, India by Kripa and Mohamed 2008, Kripa and Mohamad, 2008 revealed that women farmers in mussel farming had successfully evolved in to business managers of their own enterprises, established active liasons with banks and management of finance.

\section{CONCLUSION}

The above study shows that the participatory action model enables organization of farmers in to groups and has played a pivotal role in the successful transfer of technology for green mussels and its subsequent adoption at the field level. The Action Research Approach undertaken in Australia, which aimed at assessing the impact of advisory services on the managerial skills of farmers in the programme bears testimony to the empirical usefulness of the model. The overall G.D.E.I. of 63.03 suggests that there is further potential for effective continued use of this model in similar locations in Coastal Karnataka, since the diffusion of this technology to other end users in this region, is in the initial stage of the adoption curve with the innovators dominating the mussel groups. Women mussel farmers in the group need to be strengthened and their potential has to be harnessed on the group dimen-

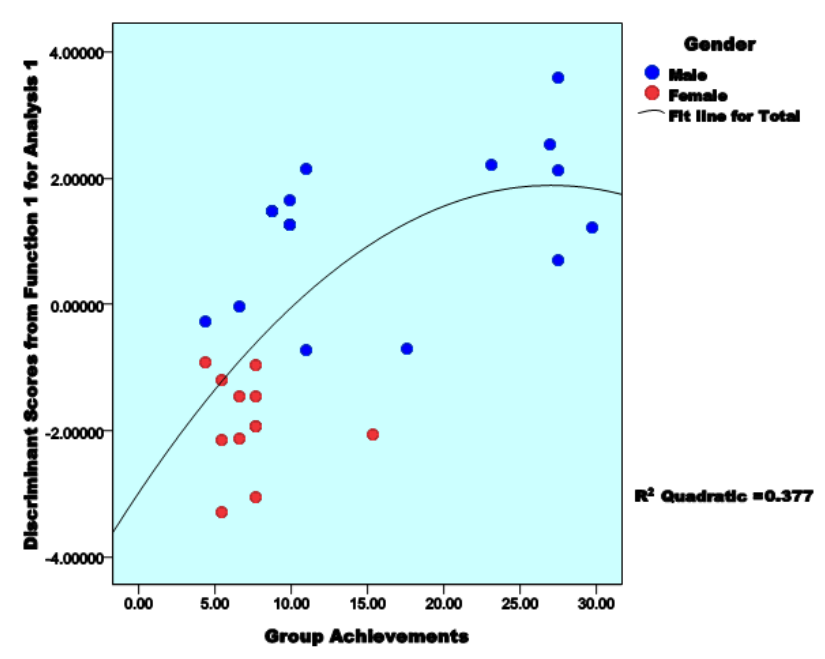

Figure 3: Scatter Plot of Group Achievements and Discriminant Score by Group 
sions such as influence, styles of influence, decision making, task function, feelings, norms, interpersonal trust and group achievements. Women mussel farmers need to shed their social inhibitions, which limit their roles in the group and which helps them to occupy the center stage not only in activities directly related to farming but also in decision making, control over resources and finance, access to managerial skills, institutional sources and markets which form the main drivers which catalyse womens involvement in collective action. Extension efforts to focus on strengthening womens role in collective action should draw valuable lessons and insights from areas where it has been highly successful such as in the adjoining State of Kerala, and how these successful ventures could be scaled up in their native groups.

\section{ACKNOWLEDGEMENT}

The authors express their gratitude to the mussel farmer groups of Karnataka and other stakeholders for successful conduct of the study. The authors express the gesture of help and support extended by the staff of the Mangalore Research Centre of CMFRI in the successful accomplishment of this venture.

\section{REFERENCES}

Cameron Donald and Shankariah Chamala 2002 Measuring Impacts of and Holistic Farm Business Management Training Program. Australian Journal of Experimental Agriculture. 44(6), 531538

Chamala S 1990 Establishing a group: A Participative Action Model, In: Working Together for land care: group management skills and strategies, S. Chamala and P.D. Mortiss, Australian Academic Press, Brisbane.

Defoer T 2002 Learning about methodology development for integrated soil fertility Management Agricultural-Systems (UK). 2002, 73(1), special issue, 5781.

Haggmann J, Chuma E, Murwira K, and
Connolly M 1999 Putting Process in to Practice: Operationalizing Participatory Extension. Network Paper Agricultural Research and Extension Network, ODI (UK). No 94, 23

Kripa V and Mohamed KS 2008 Green Mussel, Perna viridis, Farming in Kerala, India Technology Diffusion Process and Socioeconomic Impacts. Journal of the World Aquaculture Society, 39 (5). 612-624.

Laxmilatha P, Thomas S, Asokan, PK Surendranath, VG Sivadasan, MP and Ramachandran NP 2009 Mussel farming initiatives in north Kerala, India: a case of successful adoption of technology, leading to rural livelihood transformation. Aquaculture Asia, 14 (4). 9-13.

Padre S, Sudarshana and Tripp R. 2003 Reforming farm journalism: the experience of Adike Pathrike in India. Network Paper-Agricultural research and Extension Network ODI, UK. No. $128,12$.

Vipinkumar, VP 1998 Self Help Group Dynamics of Kerala Horticulture Development Programme. Unpublished Ph.D. Thesis, Division of Agricultural Extension, IARI, New Delhi, 170.

World Bank, Food and Agriculture Organization, International Fund for Agricultural Development. 2009. Gender in Extension Organisations. Agriculture Source Book, 277. 